\title{
CHARACTERIZATION OF ATMOSPHERIC THERMODYNAMIC VARIABLES BY RAMAN LIDAR IN THE FRAME OF THE INTERNATIONAL NETWORK FOR THE DETECTION OF ATMOSPheric Composition CHANGE - NDACC Benedetto De Rosa $^{1 *}$, Paolo Di Girolamo ${ }^{1}$, Donato Summa ${ }^{1}$

\author{
${ }^{1}$ Scuola di Ingegneria, Università degli Studi della Basilicata, Italy, *Email: benedetto.derosa@ unibas.it
}

\begin{abstract}
In November 2012 the Raman Lidar system BASIL, located at the Univ. of Basilicata (Potenza), was approved to enter in NDACC, with the goal of providing accurate routine measurements of the vertical profiles of atmospheric temperature and water vapour mixing ratio. In this presentation we illustrate and discuss water vapour mixing ratio and temperature measurements carried out during these four years and their comparisons with the radiosondes launched from nearby Institute IMAA-CNR (7 km away).
\end{abstract}

\section{INTRODUCTION}

Water vapour is a key atmospheric trace gas controlling weather and climate. The effects of water vapour are large in the upper troposphere and lower stratosphere (UTLS), but there are few measurements of water vapour and its long-term variation in this altitude region. Measurements in the UTLS have been traditionally guaranteed by the use of operational radiosondes or balloonborne frost-point hygrometers, the latter remaining the most reliable source of high quality water vapour measurements in the UTLS region [1], but being yet too expensive to be used on a operational basis.

For the above motivations, in the early 2000s, the international Network for the Detection of Stratospheric Change (NCSC), now Network for the Detection of Atmospheric Composition Change (NDACC), decided to include water vapour Raman lidars among its instruments.This is because, while NDACC remains committed to long-term monitoring of changes in the stratosphere, with an specific emphasis on the evolution of the ozone layer, its priorities have broadened to include issues such as the detection of trends in the overall atmospheric composition and understanding their impacts on the stratosphere and troposphere, and establishing links between climate change and atmospheric composition.

Atmospheric temperature is another parameter of interest for NDACC as in fact changes in climate and atmospheric composition have a significant impact of the thermal structure of the atmosphere.

The Raman Lidar system BASIL joined NDACC in November 2012, with the primary goal of providing accurate routine measurements of the vertical profile of both water vapour mixing ratio and temperature, these two parameters being of primary importance for the purposes of NDACC.

\section{METHODOLOGY}

Measurements discussed in this paper were performed by the Raman Lidar system BASIL in Potenza, Italy $\left(40^{\circ} 38^{\prime} 45^{\prime \prime} \mathrm{N}, 15^{\circ} 48^{\prime} 29^{\prime \prime}\right.$ E, $730 \mathrm{~m}$ above mean sea level). The system is located on the roof of the Scuola di Ingegneria at the Università degli Studi della Basilicata. BASIL is capable to perform high-resolution and accurate measurements of atmospheric water vapour and temperature, both in daytime and nighttime, based on the application of the vibrational and rotational Raman lidar techniques, respectively, in the UV $[2,3,4,5,6]$. Besides water vapour and temperature, BASIL, in its NDACC configuration, also provides measurements of particle backscatter at 355 and $532 \mathrm{~nm}$, particle extinction at $355 \mathrm{~nm}$ and particle depolarization at $355 \mathrm{~nm}$. Relative humidity measurements can also be obtained from simultaneous water vapour mixing ratio and temperature measurements [7]. A mobile version of the system has been deployed in a variety of international field campaigns $[8,9]$. A valuable contribution to NDACC from BASIL is primarily expected in terms of water vapour mixing ratio and temperature measurements. For this reason, a major emphasis has been put on these parameters, especially in terms of calibration and validation efforts. 
In the frame of NDACC, BASIL operates on a routine basis each Thursday, typically from local noon to midnight, covering a large portion of the daily cycle.

\subsection{Characterization of atmospheric thermodynamic variables}

Raman lidar measurements of the water vapour mixing ratio profile has been extensively discussed in literature (for a review see [2], [10]). The approach is based on the collection of the vibrational Raman backscattered signals from water vapour and nitrogen molecules at the two Raman wavelengths $\lambda_{\mathrm{H}_{2} \mathrm{O}}$ and $\lambda_{\mathrm{N}_{2}}$, respectively, i.e.:

$$
\begin{aligned}
& P_{\mathrm{H}_{2} \mathrm{O}}(R)=P_{0} \frac{c \Delta t}{2} \frac{A_{\text {tel }}}{R^{2}} O(R) n_{\mathrm{H}_{2} \mathrm{O}}(R) \sigma_{\mathrm{H}_{2} \mathrm{O}} T_{\lambda_{0}}(R) T_{\lambda_{\mathrm{H}_{2} \mathrm{O}}}(R) \\
& P_{\mathrm{N}_{2}}(R)=P_{0} \frac{c \Delta t}{2} \frac{A_{\text {tel }}}{R^{2}} O(R) n_{\mathrm{N}_{2}}(R) \sigma_{\mathrm{N}_{2}} T_{\lambda_{0}}(R) T_{\lambda_{N_{2}}}(R)
\end{aligned}
$$

Water vapour mixing ratio, $x_{\mathrm{H}_{2} \mathrm{O}}(R)$, can be obtained from the power ratio of water vapour to molecular nitrogen vibrational Raman signals through the expression:

$$
x_{\mathrm{H}_{2} \mathrm{O}}(R)=k \frac{P_{\mathrm{H}_{2} \mathrm{O}}(R)}{P_{\mathrm{N}_{2}}(R)} \Delta T_{\lambda_{\mathrm{H}_{2} \mathrm{O}}, \lambda_{N_{2}}}
$$

where $k$ is the lidar system calibration coefficient and $\quad \Delta T_{\lambda_{H_{2} O}, \lambda_{N_{2}}}=T_{\lambda_{N_{2}}}(R) / T_{\lambda_{H_{2} O}}(R) \quad$ is the differential transmission term, which accounts for the different atmospheric transmission at $\lambda_{\mathrm{H}_{2} \mathrm{O}}$ and $\lambda_{N_{2}}$. The calibration coefficient $k$ was determined based on the comparison between simultaneous and co-located water vapour mixing ratio profiles from the Raman lidar and radiosondes for an extended measurement sample. The vertical profile of atmospheric temperature is obtained based on the application of the rotational Raman technique in the UV using the low- and high- quantum number rotational Raman signals $P_{L O J}(z)$ and $P_{H i J}(z)$, considering the expressions:

$$
R(z)=\frac{P_{H i J}(z[T])}{P_{L o J}(z[T])} \cong \exp \left(\frac{a}{T(z)}+b\right)
$$

$$
T(z)=\frac{a}{\ln R(z)-b}
$$

with $a$ and $b$ being two calibration constants, which can be determined through the comparison of BASIL measurements with simultaneous and co-located temperature measurements from a different profiling sensor (for example a radiosonde).

\section{RESULTS}

As an example of the measurements carried out in the frame of NDACC, figure 1 illustrates the time evolution of the water vapour mixing ratio over an approx. $4 \mathrm{~h}$ period of from 16:43 UTC to 21:00 UTC on 27 November 2014. Figure 1 is plotted as a succession of $5 \mathrm{~min}$ averaged consecutive profiles. To reduce signal statistical fluctuations, vertical smoothing is applied to the data to achieve an overall vertical resolution of $150 \mathrm{~m}$.

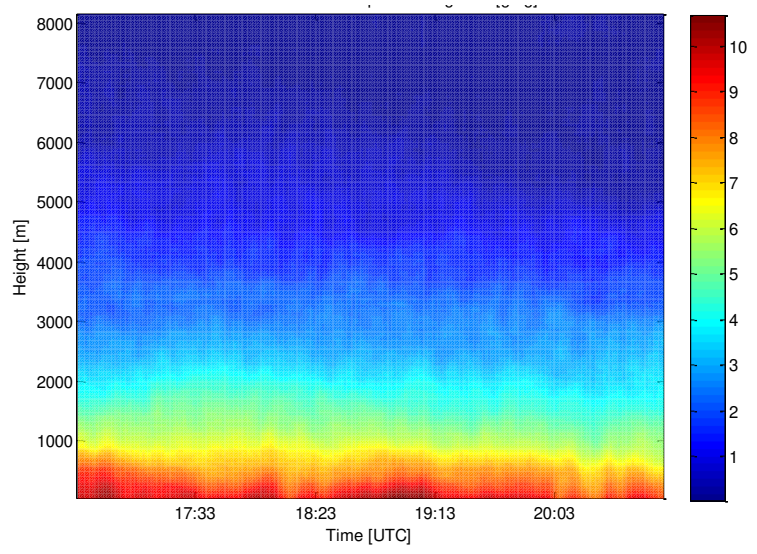

Figure 1 Time evolution of the water vapour mixing ratio over an approx. 4 heriod of from 16:43 UTC to 21:00 UTC on 27 November 2014.

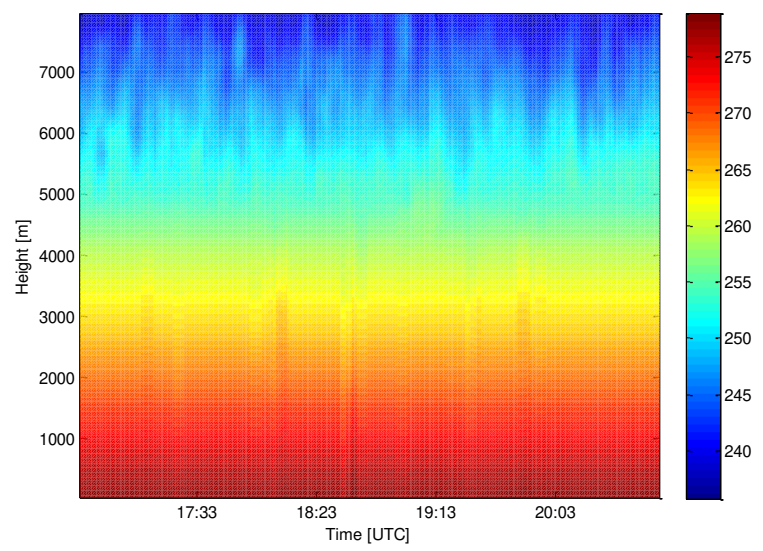

Figure 2 Time evolution of the temperature from 16:43 UTC to 21:00 UTC on 27 November 2014. 
Figure 2 shows the evolution of atmospheric temperature in the same time interval of figure 1. In this case, in order to obtain a sufficiently high signal statistics, it was necessary to consider a vertical resolution of $300 \mathrm{~m}$. Figure 1 reveals the presence of a humid layer extending up to $1.5 \mathrm{~km}$, identifying the convective boundary-layer. The top of the convective boundary layer is clearly visible also in figure 2 , being identified by the strong temperature gradient at $1.5 \mathrm{~km}$. Comparisons between the Raman lidar at Scuola di Ingegneria and the radiosondes launched from IMAA-CNR (7 km away) were carried out in the period 9 October 2014- 7 May 2015. An overall number of 11 comparisons were possible. The sample is limited because before 20 November 2014 radiosondes were not routinely launched from IMAA-CNR (routine launches are carried out on Thursday, i.e. on the same day when BASIL is operated in the frame of NDACC). Figure 3 illustrates the vertical profiles of water vapour mixing ratio (panel a) and temperature (panel b) on 27 November 2014, considering an integration time of approx. $4 \mathrm{~h}$ between 16:43 and 21:00 UTC. The vertical resolution is $150 \mathrm{~m}$ for both water vapour and temperature measurements. For comparison, the almost simultaneous water vapour mixing ratio and temperature profiles measured by a radiosonde launched from of Tito Scalo at 18:00 UTC on 27 November 2014 are also included in the figure. The agreement between BASIL and the radiosonde is good for both parameters, especially when considering the distance between the two sites. The water vapour mixing ratio profile from BASIL is found to reach approx. $12 \mathrm{~km}$, with a sensitivity level of 0.05 $\mathrm{g} / \mathrm{kg}$. The capability to reach $12 \mathrm{~km}$ and a sensitivity level of $0.03-0.05 \mathrm{~g} / \mathrm{kg}$ have been observed in most of the $2 \mathrm{~h}$ water vapour profiles measured in clear sky conditions by BASIL in the frame of NDACC. When considering measurements integrated over the entire night, the lidar profile is found to extend up to approx. 18$20 \mathrm{~km}$. More results from this measurement effort, also focusing on the statistical analysis on the collected data, will be illustrated and discussed at the Conference. Temperature profiles are typically measured by BASIL with a vertical resolution of $300 \mathrm{~m}$. Up to $8 \mathrm{~km}$ the agreement with the radiosonde is very good. Considering the 11 possible comparisons between BASIL and the radiosondes in the period 9 October 2014- 7 May 2015 , the water vapour mixing ratio mean relative bias was estimated (figure 4).
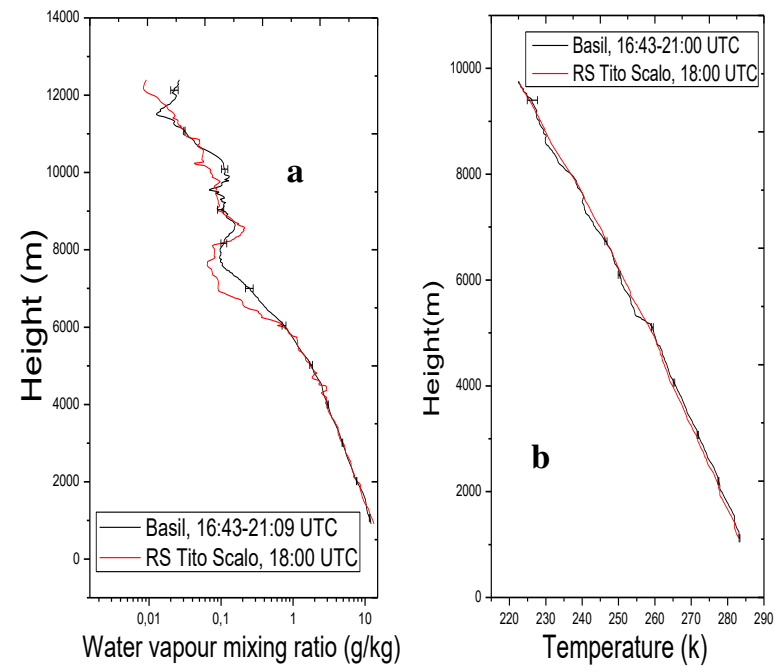

Figure 3 Vertical profiles of water vapour mixing ratio (panel a) and temperature (panel b) as obtained considering a time integration between 16:43 and 21:00 UTC on 27 November 2014, together with the simultaneous profile as measured by a radiosonde launched from the nearby site of Tito Scalo at 18:00 UTC on 27 November 2014.

Results in the figure reveal that, with the only exception of a couple of points, bias values are within $\pm 10 \%$ up to $14 \mathrm{~km}$. These results demonstrate the capability of BASIL to comply with the NDACC observational requirements.

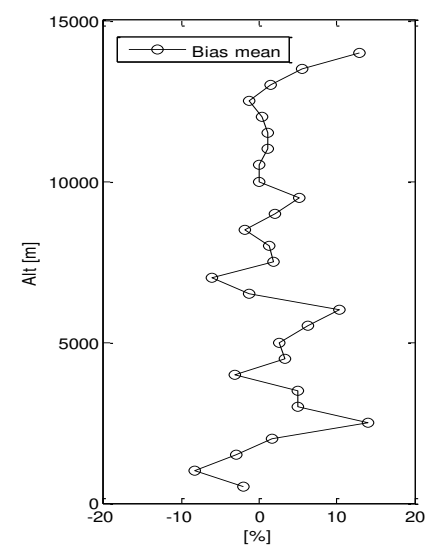

Figure 4 Vertical profile of the vapour mixing ratio mean bias (expressed in \%) between BASIL and the radiosondes

Figure 5 illustrates the vertical profiles of the mean relative and absolute bias and RMS deviation of BASIL vs. the radiosondes for temperature measurements as obtained 
considering the above mentioned 11 days. Above the planetary boundary layer up to $9.5 \mathrm{~km}$ the value are low, in particular the bias absolute are within $\pm 1 \mathrm{~K}$.
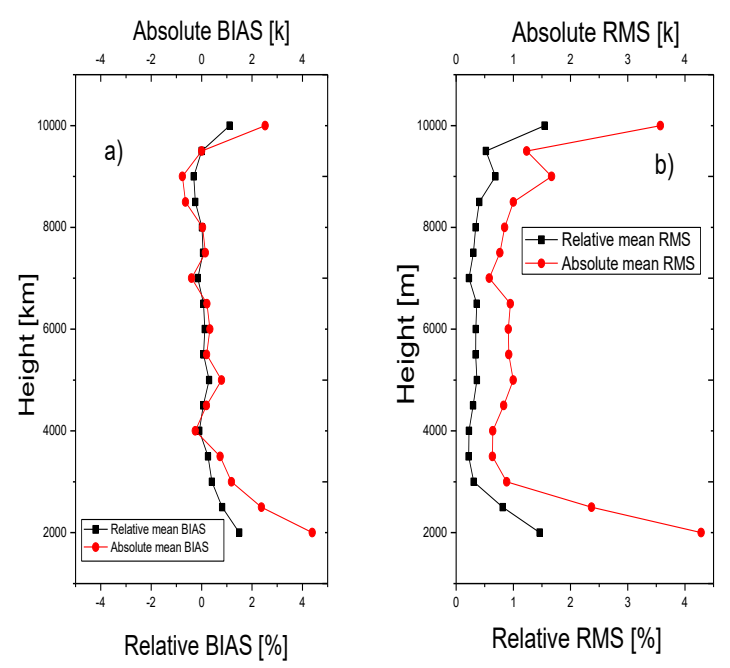

Figure 5 Vertical profiles of the relative and absolute mean bias (left panel) and RMS deviation (right panel) for the temperature measurements

\section{ACKNOWLEDGEMENTS}

We wish to warmly thank Istituto di Metodologie per l'Analisi Ambientale, Consiglio Nazionale delle Ricerche, in Tito Scalo, for the provision of the radiosnde data.

\section{References}

[1] Vomel, H., H. Selkirk, L. Miloshevich, J. Valverde-Canossa, J. Valdes, E. Kyro, R. Kivi, W. Stolz, G. Peng, and J. A. Diaz,2007: Radiation dry bias of Vaisala RS92 humidity sensor. J. Atmos. Oceanic Technol., 24, $953-$ 963.

[2] Whiteman, D. N., 2003a: Examination of the traditional Raman lidar technique. I. . Evaluating the temperature-dependent lidar equations, Appl.Optics,42,2571-2592.

[3] Behrendt, A. and Reichardt, J.: Atmospheric temperature profiling in the presence of clouds with a pure rotational Raman lidar by use of an interference-filter-based polychromator, Appl Optics,39,1372-1378,2000.

[4] Di Girolamo, P., R. Marchese, D. N. Whiteman, B. B. Demoz, 2004: Rotational
Raman Lidar measurements of atmospheric temperature in the UV. Geophys. Res. Lett. 31,doi:10.1029/2003GL018342.

[5] Di Girolamo, P., A. Behrendt, and V. Wulfmeyer, 2006. Spaceborne profiling of atmospheric temperature and particle extinction with pure rotational Raman lidar and of relative humidity in combination with differential absorption lidar: performance simulations, Appl. Opt. $\quad$ 45, 2474-2494, doi:10.1364/AO.45.002474.

[6] Bhawar, R., P. Di Girolamo, D. Summa, C. Flamant, D. Althausen, A. Behrendt, C. Kiemle, P. Bosser, M. Cacciani, C. Champollion, T. Di Iorio, R. Engelmann, C. Herold, Müller, D., S. Pal, M. Wirth, V. Wulfmeyer, 2011: The Water Vapour Intercomparison Effort in the Framework of the Convective and Orographically-Induced Precipitation Study: Airborne-to-Ground-based and airborne-to-airborne Lidar Systems, Quarterly Journal of the Royal Meterological Society 137,325-348.

[7] Di Girolamo P., D. Summa, R.-F Lin, T. Maestri, R. Rizzi, G. Masiello, 2009: UV Raman Lidar measurements of relative humidity for the characterization of cirrus cloud microphysical properties, Atmos. Chem. Phys. 9, 8799-8811, doi: 10.5194/acp-9-8799-2009.

[8] Di Girolamo, P., C. Flamant, M. Cacciani, E. Richard, V. Ducrocq, D. Summa, D. Stelitano, N. Fourrié and F. Saïd, 2016: Observation of low-level wind reversals in the Gulf of Lion area and their impact on the water vapour variability, Q. J. Roy. Meteor. Soc. 142 (Suppl 1), 153-172, doi: 10.1002/qj.2767.

[9] P. Di Girolamo, D. Summa, B. De Rosa, M. Cacciani, A. Scoccione, A. Behrendt, V. Wulfmeyer, 2017: Characterization of Boundary Layer Turbulent Processes by Raman Lidar: Demonstration of the Measurement Capabilities of the Raman Lidar System BASIL, Atmos. Chem. Phys. 17, 745-767, doi:10.5194/acp-17-745-2017.

[10] Whiteman, D. N., 2003b Examination of the traditional Raman lidar technique. II. . Evaluating the ratios for water vaour and aerosols.temperature-dependent lidar equations, Appl.Optics,42,2593-2608. 